\title{
Effect of Different Stocking Density of Snakehead Fish (Channa striata) Cultured in Recirculation Aquaculture System
}

\author{
Dewi Puspaningsih ${ }^{1, *}$, Lies Setijaningsih ${ }^{1}$, Eri Setiadi ${ }^{1}$, and Imam Taufik ${ }^{1}$ \\ ${ }^{1}$ Research Institute for Freshwater Aquaculture and Fisheries Extention, J1. Sempur No.1, Bogor, \\ 16154, West Java, Indonesia
}

\begin{abstract}
In Indonesia, the use of such recirculating aquaculture systems (RAS) is rapidly increasing. The purpose of this study was to investigate the growth, blood chemistry, and water quality of snakehead fish (C. striata) maintained in RAS at varied stocking densities. The RAS was established at the Bogor-based Research Institute for Freshwater Aquaculture and Fisheries Extension. The study employed a completely randomized study using 3 various densities: A). 1 individual $\left.\mathrm{L}^{-1}, \mathrm{~B}\right) .3$ individual $\mathrm{L}^{-1}$ and c). 6 individuals $\mathrm{L}^{-1}$, each using three replications. The average weight and length of snakehead fish used is $1.50 \pm 0.63 \mathrm{~g}$ and $6.20 \pm 0.94 \mathrm{~cm}$. Growth performances such as survival rate, weight, and length gain, food conversion ratio, specific growth rate, and final biomass were observed during the research. Blood chemistry parameters analyzed were blood glucose, triglycerides, and total protein. The water quality characteristics were evaluated: $\mathrm{pH}$, temperature, dissolved oxygen, total ammonia nitrogen, nitrate, nitrite, and orthophosphate. The analysis indicates that snakehead fish's growth performances and blood chemistry parameters differed considerably $(\mathrm{P}<0.05)$ across all density treatments, with 3 individual $\mathrm{L}^{-1}$ showing the best growth performances. The RAS utilized in snakehead fish culture kept the water quality parameters steady throughout the study.
\end{abstract}

\section{Introduction}

Nowadays, aquaculture intensification has become very popular, and it is characterized by high stocking density and the use of artificial feed to feed the fish. All living things require nitrogen, and fish feed with a high protein content is the primary nitrogen supply for fish farming [1]. Only around $25 \%$ of the nitrogen input from the fish feed is converted to fish biomass in the aquaculture system. In comparison, the remaining $70 \%$ is excreted into the surrounding medium or environment as waste [2]. From $100 \%$ feed given to the fish, as much as $20 \%$ become food waste, only about $80 \%$ consumed by the fish, which were

\footnotetext{
*Corresponding author: d_puspaningsih@yahoo.com
} 
divided into $65 \%$ will become excretory waste, $10 \%$ will become fecal waste, and only about $25 \%$ retained by the fish [3].

Increased use of high protein content in intensive aquaculture will also cause higher waste. Higher waste of snakehead fish culture can be a problem if we dispose the waste into the environment and can also harm the fish health, thus can cause the death of the fish. One of the solutions to manage the snakehead fish waste is using Recirculation Aquaculture System (RAS). RAS has existed since the mid-1950s, RAS conserve both water and land, can be located close to the market [4], RAS makes intensive fish production compatible with environmental sustainability [5], and RAS made better in water quality and increase fish production [6].

The snakehead (Channa striata) is a carnivorous, air-breathing fish, is a precious food fish in Asia, often cultivated in the ponds at densities 40-80 fingerling $\mathrm{m}^{-2}$ [7]. The snakehead has long been commercially cultured in many countries because it has nice tasty meat, good market value, and medicinal factor [8]. It's also one of the freshwater fish possessing albumin helpful content for human health, wound healing [9]; [10], had an albumin and zinc content that is good for health [11]. Mass production of snakehead fish from larvae rearing stage, first and second phase of fry culture, also the fingerling culture up to consumed at the table of this fish had become exciting topics for some countries such as in Malaysia [12], in India [13]; [10], Bangladesh [14], Indonesia [15]; [16], in China [17]. Snakehead fish was carnivorous fish that fed protein content between $38-44 \%$ [18]; [19].

Several studies have been undertaken on fish stocking densities and their effects. Most participants agreed that increased stocking densities had a strong influence on fish growth. [20]. High stocking numbers were linked to a drop in water quality, according to the study. However, multiple studies have found that increasing stocking density while keeping consistent water quality during the culture had no harmful impact on the fish. As is known, stocking density is one of the environmental stressors in fish. Measurement of secondary biochemical indicators, such as hematological characteristics, can assess the secondary reactions of fish to the stressors [21]. Fluctuation of fish blood biochemistry can monitor improper environmental conditions and the presence of stressing factors. Further research is also needed to recommend the more appropriate stocking densities and culture technique of snakehead fish culture [12]. The research conducted to study the stocking density's difference effect of snakehead fish cultured in RAS has never been done. The purpose of this study was to see how snakehead fish (Channa striata) cultivated at various stocking densities affected growth performance, blood chemistry, and water quality in RAS.

\section{Methodology}

The study was carried out in Cibalagung Bogor, Research Institute for Freshwater Aquaculture and Fisheries Extention (RIFAFE), Bogor, West Java, Indonesia, at the Aquaculture and Toxicology Environmental Research Installation.

\subsection{Materials}

Snakeheads were used as test fish, with an average weight of $1.50 \pm 0.63 \mathrm{~g}$ and an average fish length of $6.20 \pm 0.94 \mathrm{~cm}$. The RAS design-build in the RIFAFE's research station.

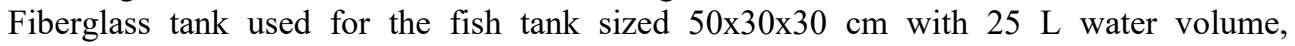
completed with aeration equipment, and covered with nets to avoid the fish jumping out of the mediums. Fish were acclimatized in fiber tanks for 2 weeks.

Physical and biological filters are included in the RAS design. A round bucket with 30 $\mathrm{cm}$ in diameter and $25 \mathrm{~cm}$ in height was used for the Physical and biological filter. The fish 
tank and the filter were connected with 5" PVC pipe. The physical filter was consisted of limestone and gravel stone, while the biological filter with bio balls. The RAS design was also completed with a water pump, faucet, and a transparent shelter to anticipate the effects of adverse climates on water quality fluctuations in the culture media.

\subsection{Methods}

The study used a completely randomized design (CRD) with three treatments of varied snakehead fish stocking densities (per Liter), i.e., A (1 fish), B (3 fish), and C (6 fish), each treatment had three replications. Fish cultured for 8 weeks. The snakehead fish were fed with commercial fish pellets with a chemical ingredient studied previously [22]. Test parameters observed for fish growth performances included:

$$
\mathrm{SR}(\%)=(\mathrm{Nt} / \mathrm{No}) \times 100
$$

SGR $(\%)=$ Ln final bodyweight of the fish - Ln initial body weight of the fish)/Length of days experiment $\mathrm{x} 100$

$\mathrm{FCR}=$ Dry feed fed $(\mathrm{g}) /($ Final body weight of the fish + Dead fish weight $)-$ Initial bodyweight of the fish

Length or weight gain $\left(\mathrm{cm} \mathrm{fish}^{-1} / \mathrm{g}\right.$ fish $\left.{ }^{-1}\right)=$ Fish's final length or Fish's final weight initial fish length or initial fish weight

Blood glucose, triglycerides, and total protein serum were detected in the blood of snakehead fish. $\mathrm{pH}$, temperature, DO (dissolved oxygen), nitrite, total ammonia nitrogen (TAN), nitrate, and orthophosphate are among the water quality characteristics assessed. Water quality parameters and fish growth performances were observed every 2 weeks. At the end of the research, the blood chemistry parameters of the snakehead fish were analyzed.

Data on water quality parameters during the research were analyzed descriptively, while data on fish growth performances and blood chemistry were analyzed using ANOVA (Analysis of Variance). If there were significant differences among the stocking density treatments, Duncan's multiple interval test will continue at a $95 \%$ of confidence level.

\section{Results}

\subsection{Snakehead fish growth performances}

At the end of this research, snakehead fish growth performances were investigated (Table $1)$.

Table 1. Snakehead fish growth performances at different stocking densities.

\begin{tabular}{|l|c|c|c|}
\hline \multirow{2}{*}{ Parameters } & \multicolumn{3}{|c|}{ Stocking density treatments } \\
\cline { 2 - 4 } & $\mathrm{A}$ & $\mathrm{B}$ & $\mathrm{C}$ \\
\hline SR $(\%)$ & $82.67 \pm 2.31 \mathrm{~b}$ & $86.67 \pm 2.67 \mathrm{~b}$ & $59.11 \pm 1.02 \mathrm{a}$ \\
\hline SGR $(\%)$ & $2.67 \pm 0.01 \mathrm{~b}$ & $2.94 \pm 0.03 \mathrm{c}$ & $2.29 \pm 0.01 \mathrm{a}$ \\
\hline FCR & $1.25 \pm 0.02 \mathrm{c}$ & $1.13 \pm 0.02 \mathrm{a}$ & $1.19 \pm 0.03 \mathrm{~b}$ \\
\hline Weight gain $(\mathrm{g})$ & $5.19 \pm 0.05 \mathrm{~b}$ & $6.29 \pm 0.14 \mathrm{c}$ & $3.89 \pm 0.02 \mathrm{a}$ \\
\hline Length gain $(\mathrm{cm})$ & $3.30 \pm 0.06 \mathrm{~b}$ & $3.40 \pm 0.32 \mathrm{~b}$ & $2.80 \pm 0.08 \mathrm{a}$ \\
\hline Final biomass $(\mathrm{g})$ & $138.30 \pm 2.95 \mathrm{a}$ & $506.39 \pm 13.51 \mathrm{c}$ & $478.15 \pm 6.09 \mathrm{~b}$ \\
\hline
\end{tabular}


At the 5\% confidence level, the numbers followed by different letters on the same line suggest a significant difference (Duncan's test).

\subsection{The water quality parameters}

Temperature (Fig. 1.), pH (Fig. 2.), and DO (Fig. 3.) show water quality characteristics measured at the fish tank and after filtering during the experiment.
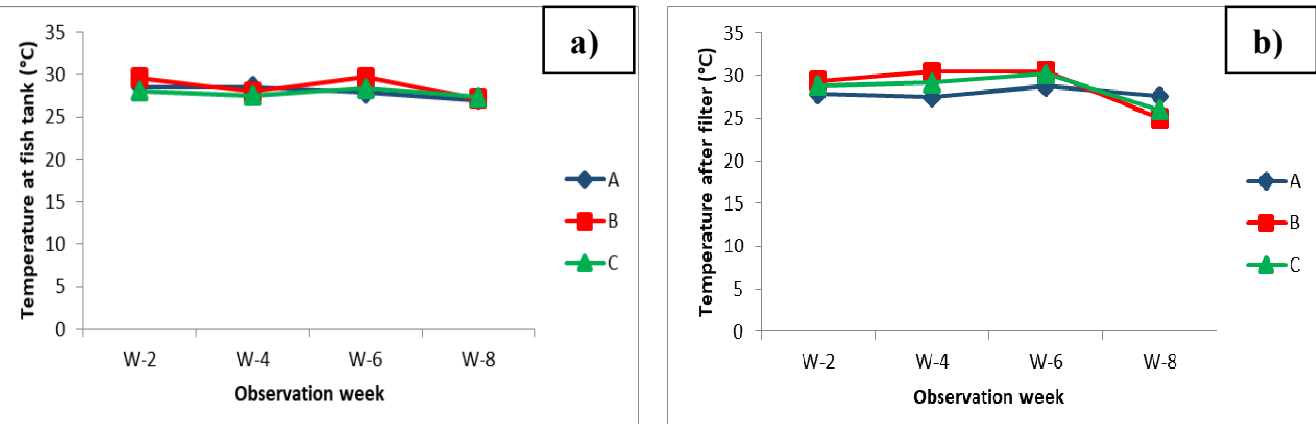

Fig. 1. Temperature value, a)at the fish tank, b) after the filter.

DO concentration at this experiment ranged between $2.4-4.93 \mathrm{mg} \mathrm{L}^{-1}$ (at the fish tank), 2.91-5.14 $\mathrm{mg} \mathrm{L}^{-1}$ (after the filter).
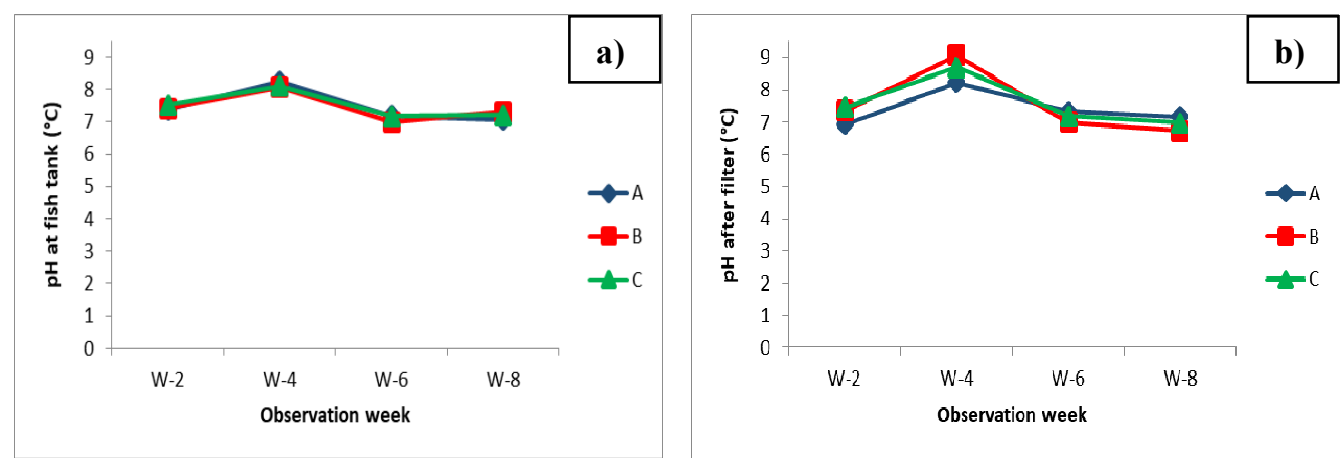

Fig. 2. pH value, a) at fish tank, b) after filter.
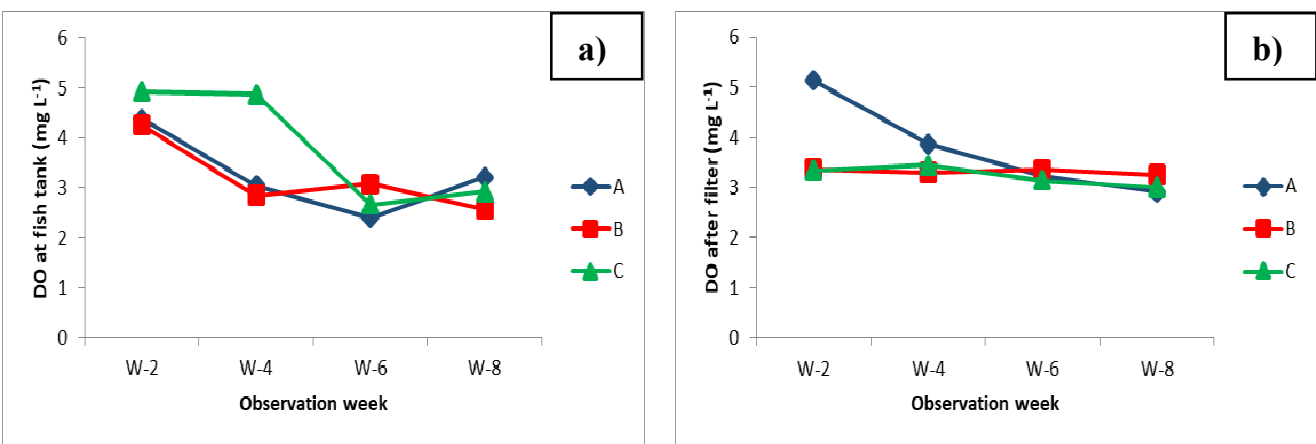

Fig. 3. DO concentration, a) at the fish tank, b) after the filter.

Other water quality parameters such as TAN, nitrite, nitrate, and orthophosphate concentration can be seen respectively in Fig. 4, 5, 6, 7. 

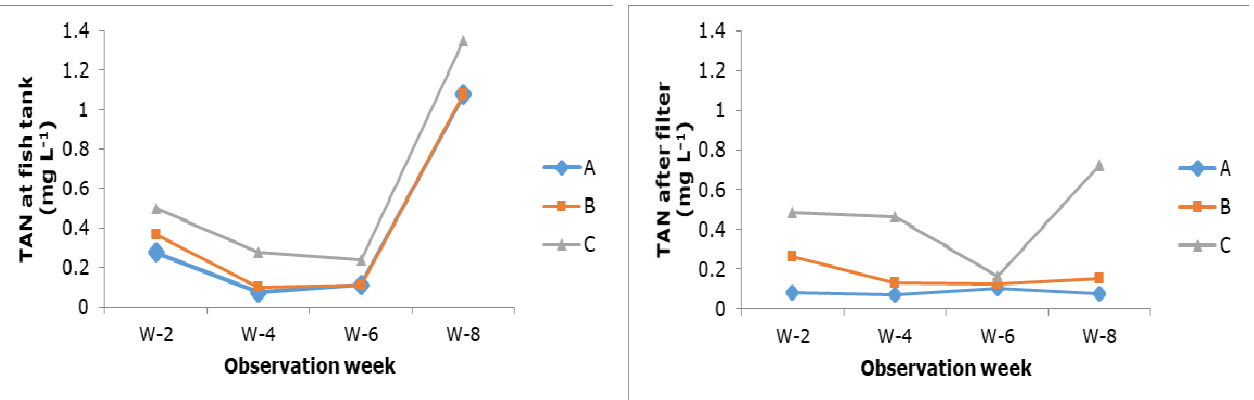

Fig. 4. TAN concentration at all density treatment.
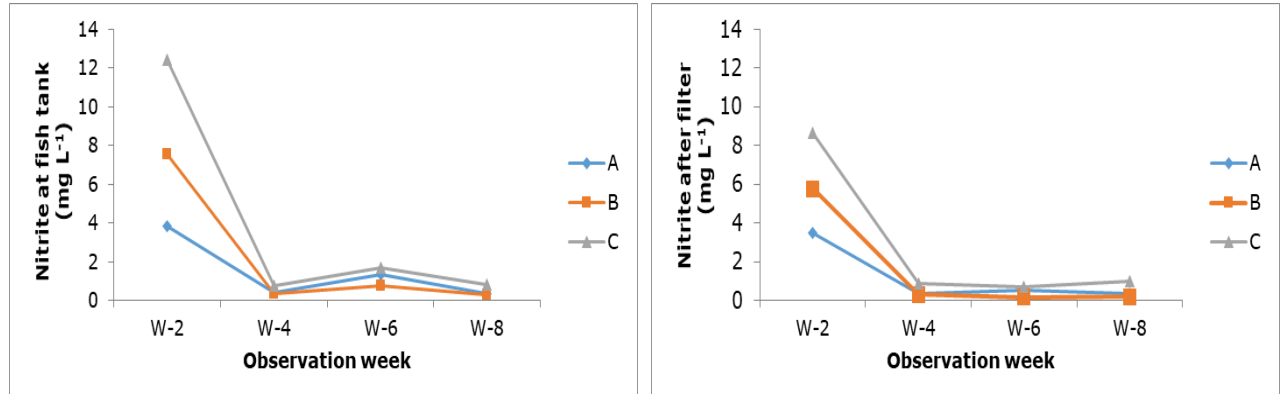

Fig. 5. Nitrite concentration at all density treatment.
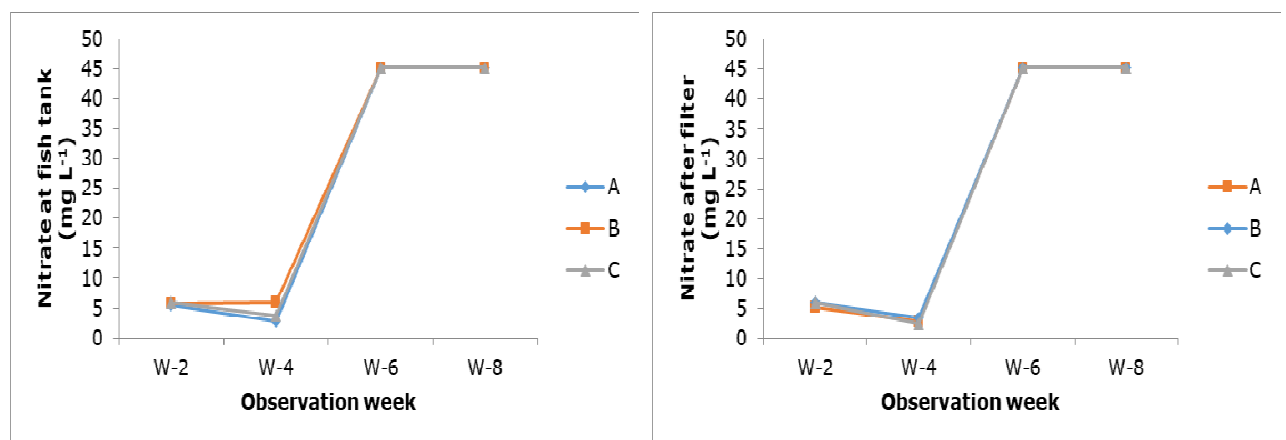

Fig. 6. Nitrate concentration at all density treatment.
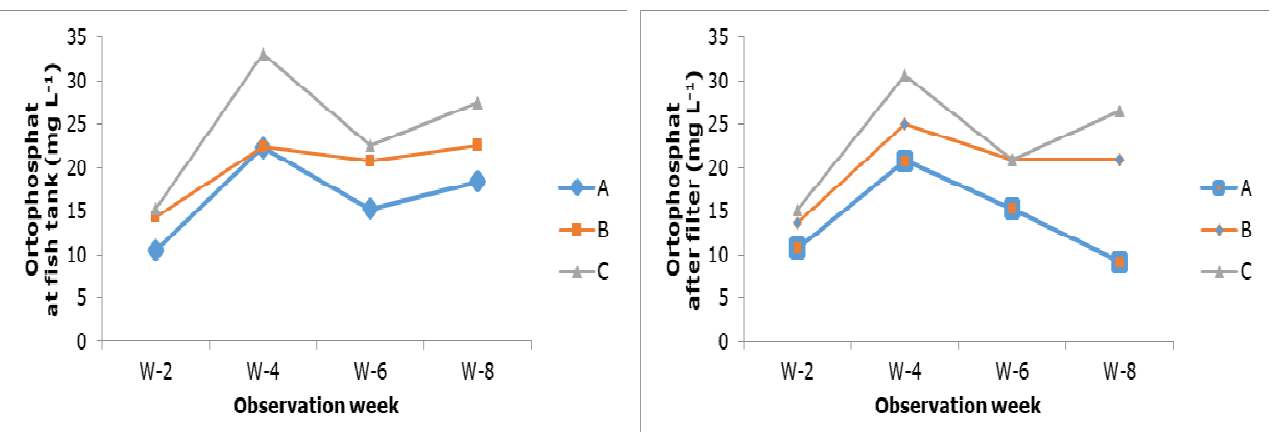

Fig. 7. Orthophosphate concentration at all density treatment. 


\subsection{Blood chemistry}

The blood chemistry of snakehead fish in this experiment can be seen in Table 2. In general, there was no significant difference $(\mathrm{P}<0.05)$ in total protein serum concentration in the blood between the density treatments.

Table 2. Blood chemistry of snakehead fish at all density treatment.

\begin{tabular}{|l|c|c|c|}
\hline \multirow{2}{*}{ Parameters } & \multicolumn{3}{|c|}{ Treatment } \\
\cline { 2 - 4 } & $\mathrm{A}$ & $\mathrm{B}$ & $\mathrm{C}$ \\
\hline Blood glucose $\left(\mathrm{mg} \mathrm{dl}^{-1}\right)$ & $45.50 \pm 1.50 \mathrm{a}$ & $72.33 \pm 3.06 \mathrm{~b}$ & $113.5 \pm 1.50 \mathrm{c}$ \\
\hline Triglicerydes $\left(\mathrm{mg} \mathrm{dl}^{-1}\right)$ & $81.33 \pm 7.09 \mathrm{a}$ & $124.00 \pm 3.61 \mathrm{~b}$ & $216.67 \pm 15.28 \mathrm{c}$ \\
\hline Total protein serum $\left(\mathrm{g} \mathrm{dl}^{-1}\right)$ & $2.83 \pm 0.76 \mathrm{~b}$ & $1.70 \pm 0.2 \mathrm{a}$ & $2.50 \pm 0.50 \mathrm{ab}$ \\
\hline
\end{tabular}

At the $5 \%$ confidence level, the numbers followed by different letters on the same line indicate a substantial difference (Duncan's test).

\section{Discussion}

According to the findings, the $\mathrm{B}$ treatment had the best survival rate $(86.67 \%)$, with no significant difference $(\mathrm{P}>0.05)$ from treatment $\mathrm{A}(82.67 \%)$, but a significant difference $(\mathrm{P}<0.05)$ from treatment $\mathrm{C}$. $(59.11 \%)$. The same trend was seen in the length gain parameter, which indicated a significant difference $(\mathrm{P}<0.05)$ between treatment $\mathrm{B}(3.40 \mathrm{~cm})$ and treatment $\mathrm{C}(2.80 \mathrm{~cm})$, but no significant difference $(\mathrm{P}>0.05)$ between treatment $\mathrm{A}$ and treatment $\mathrm{C}(3.30 \mathrm{~cm})$. Observation on SGR, FCR, weight gain, and final biomass of snakehead fish at the end of the research showed the same trend, where B treatment showed the best value, compared to $\mathrm{A}$ and $\mathrm{C}$ treatment. The $\mathrm{B}$ treatment differed significantly $(\mathrm{P}<0.05)$ from the $\mathrm{A}$ and $\mathrm{C}$ treatments for those parameters.

The growing value in this experiment, such as SR, SGR, weight gain, length gain, and final biomass of snakehead fish, was followed by decreasing of FCR. This phenomenon showed the same with [12], which mentions that when SR reaches $67.33 \%$ FCR value is 2.10, while SR comes $54.67 \%$ FCR value is 2.68 . The same tendency showed from [18], which mentioned that at SGR 9.31\% FCR value is 2.55 , while at SGR $6.79 \%$ FCR value is 3.45. The FCR value in one's experiment might be affected by stocking density. The higher the stocking density, the usually will affect the higher the FCR value [12].

The FCR value of snakehead fish feed with commercial fish feed at $5 \%$ of body weight was 1.0 [12]. In this experiment, the snakehead fish growth performance showed that B treatment ( 3 fish $\mathrm{L}^{-1}$ ) was obtained the highest in SR, SGR, weight gain, length gain, and final biomass, also low in FCR value. Snakehead fish could be cultured with a stocking density of up to 3 fish $\mathrm{L}^{-1}$ to maximize high productivity and to minimize nutrient waste without affecting the snakehead's survival rate.

Overall, the fish tank and filter temperature data ranged from $25.0-30.55{ }^{\circ} \mathrm{C}$, and $\mathrm{pH}$ values ranged from 6.725-9.075. Increased of $\mathrm{pH}$ only measured at the $2^{\text {nd }}$ observation (week 4), this phenomenon indicated that $\mathrm{pH}$ on the RAS was still adaptively fluctuated until it showed stability again on the next observation. In all density treatment on the fish tank, DO concentration showed higher at the first observation, then revealed decreased at the next observation. Although DO in the fish tank outputs has been kept above the necessary level, other water quality parameters that could impair fish survival and growth if water flows are not regulated according to biomass also a potential [20]. Overall, TAN concentration at the fish tanks in all density treatment showed higher than the filter concentration, and the same phenomena also happen in nitrite, nitrate, and orthophosphate concentration. This indicated that the filter design in this RAS experiment maintained the water quality stable during the experiment. It happens in all design of RAS technology, where the system needs some time to adapt until the water quality is stable for fish culture. 
However, its concentration showed high stability on the filter, meaning that the critical component in RAS is filtration (physical and biological).

Blood glucose levels and triglycerides showed an increase with the increase in the stocking density of snakehead fish. The snakehead fish's plasma glucose level rises as the stocking density rises [23]. The mobilization of glucose by the snakehead fish in response to high stocking density stress could cause these increases. Stress causes changes in blood glucose metabolism, which is a frequent response. Blood glucose level and blood cortisol are two of the most common stress indicators. Still, due to their high variability in research, they must be supplemented with other stress parameters to obtain a complete blood profile of the fish's stress status, and their levels are increased in any adverse situations [23]. The maximum stocking density may cause stress, which may increase the fish's energy requirements and mobilization of the fish's energy stores [24]. Knowledge of hematological blood parameters is an essential tool that may be used to evaluate physiological and pathological changes in fish and detect fish health problems [25]; [26]. Previous research on fish blood hematology showed that blood parameter levels could be affected by variation in water temperature and oxygen concentration [26], these phenomena also happen in this experiment.

\section{Conclusion}

The recirculation system used in the culture of snakehead fish made the water quality parameters measured stable during the research. Using the recirculation aquaculture system, 3 fish L-1 in the stocking density showed the best growth performances on the snakehead fish culture.

\section{References}

1. L.M.P. Valente, F. Linares, J.L.R Villanueva, J.M.G. Silva, M. Espe, C. Escorcio, M.A. Pires, M.J. Saavedra, P. Borges, F. Medale, B. Alvares-Blazquez, J.B. Peleteiro, Aquac. 318, 1-2 (2011)

2. J.A. Hargreaves, Aquac. Eng. 34, 344-363 (2006)

3. C. Frid, M. Dobson, Ecology of aquatic management (Prentice Hall. Pearson Education, Hoboken, 2002)

4. L.A. Helfrich, G. Libey, Fish farming in resirculating aquaculture systems (Department of Fisheries and Wildlife Sciences, Virginia Tech, 1991)

5. C.I.M. Martin, E.H. Eding, M.C.J. Verdegem, L.T.N. Heinsbroek, O. Schneider, J.P. Blancheton, R.E. d Orbcastel, J.A.J. Verreth, Aquac. Eng. 43, 3 (2010)

6. S.Y. Zhang, G. Li, H.B. Wu, X.G. Liu, Y.H. Yao, L. Tao, H. Liu, Aquac. Eng. 45, 93102 (2011)

7. K.L. Wee, The biology and culture of snakeheads (Muir and R.J. Roberts, eds, Westview Press, Boulder, 1982)

8. K. Marimuthu, M.A. Haniffa, Infofish Intl. 2, 16-22 (2004)

9. Firlianty, E. Suprayitno, H. Nursyam, Hardoko, A. Mustafa, Intl. J. Sci. Tech. (IJSTE). 2, 4 (2013)

10. P.P. Srivastava, R. Dayal, S. Chowdhary, J.K. Kena, S. Raizada, P. Sharma, Onl. J. Anim. F. Res. 2, 2 (2012)

11. A. Mustafa, M.A. Widodo, Y. Kristianto, Intl. J. Sci. Tech. 1, 2 (2012)

12. M.A. Rahman, A. Arshad, S.M.N. Amin, Aquac. Res. 43, 2 (2012) 
13. S. Zehra, M.A. Khan, Aquac. Intl. 20, 383-395 (2012)

14. M.N. Sarowar, M.Z.H. Jewel, M.A. Sayeed, M.F.A. Mollah, Int. J. BioRes. 1, 3 (2010)

15. D. Muthmainnah, $4^{\text {th }}$ Intl. Conf. Bio. Env. Chem. 58 (2013)

16. Wahyu, E. Supriyono, K. Nirmala, E. Harris, Ind. Ich. J. 15, 2 (2015)

17. X. Zhuo, R. Liang, Y. Chen, G. Huang, D. Yu, J Zou, Biochem. Syst. Eco. 43 (2012)

18. P.P. Srivastava, R. Dayal, S. Chowdhary, J.K. Jena, S. Raizada, P. Sharma, Online. J. Anim. Feed. Res. 2, 2 (2011)

19. M.A. Rahman, S. Awal, IJAAEE. 3, 1 (2016)

20. C.D. Hosfeld, J. Hammer, S.O. Handeland, S. Fivelstad, S.O. Stefansson, Aquac. 294, 236-241 (2009)

21. M. Naderi, H. Jafaryan, S. Jafaryan, Iran. J. Aqua. Anim. Health. 3, 2 (2017)

22. D. Puspaningsih, E. Supriyono, K. Nirmala, I. Rusmana, C. Kusmana, A. Widiyati, O. Akua. 14, 2 (2018)

23. E.K. Ajani, S.B. Setufe, O.O. Oyebola, Af. J. Food Sci. 9, 2 (2015)

24. E. Salas-Leiton, V. Anguis, B. Martin-Antonio, D. Crespo, J.V. Planas, C. Infante, J.P. Canavate, M. Manchado, Fish. Shellfish Immun. 28, 2 (2010)

25. A.D. Talpur, M.B. Munir, A. Mary, R. Hashim, Aquac. 426-427, 14-20 (2014)

26. Z.M. Kohanestani, A. Hajimoradloo, R. Ghorbani, S. Yulghi, A. Hoseini, M. Molaee, World. J. Fish. Mar. Sci. 5, 121-126 (2013) 